\title{
Clinical findings of Talaromyces marneffei infection among patients with anti-interferon-y immunodeficiency: a prospective cohort study
}

\section{Zhao-Ming Chen}

The First Affiliated Hospital of Guangzhou Medical University

Zheng-Tu Li

The First Affiliated Hospital of Guangzhou Medical University

Shao-Qiang Li

The First Affiliated Hospital of Guangzhou Medical University

\section{Wei-Jie Guan}

The First Affiliated Hospital of Guangzhou Medical University

\section{Ye Qiu}

The Affiliated Tumor Hospital of Guangxi Medical University

\section{Zi-Ying Lei}

The Third Affiliated Hospital of Sun Yat- Sen University

\section{Yang-Qing Zhan}

The First Affiliated Hospital of Guangzhou Medical University

\section{Hua Zhou}

Zhejiang University School of Medicine

\section{Sheng Lin}

Fujian Provincial Hospital, Shengli Clinical Medical College of Fujian Medical University

\section{Xinni Wang}

The First Affiliated Hospital of Guangzhou Medical University

\section{Zhun Li}

The First Affiliated Hospital of Guangzhou Medical University

\section{Feng Yang}

The First Affiliated Hospital of Guangzhou Medical University

\section{Wen Zeng}

The First Affiliated Hospital of Guangxi Medical University

\section{Ye Lin}

The First Affiliated Hospital of Guangzhou Medical University

\section{Jing Liu}

The Third Affiliated Hospital of Sun Yat- Sen University

Jian-Quan Zhang 
The Eighth Affiliated Hospital, Sun Yat-Sen University

Feng Ye ( $\sim$ tu276025@gird.cn)

The First Affiliated Hospital of Guangzhou Medical University

\section{Research Article}

Keywords: anti-IFN-y autoantibodies, Talaromyces marneffei, clinical features, clinical outcome

Posted Date: May 14th, 2021

DOl: https://doi.org/10.21203/rs.3.rs-494898/v1

License: (c) (1) This work is licensed under a Creative Commons Attribution 4.0 International License. Read Full License 


\section{Abstract}

Background: Talaromyces marneffei (T. marneffei) infection has been associated with adult-onset immunodeficiency due to anti-IFN-y autoantibodies. We aimed to investigate the clinical features of nonHIV-infected patients with T. marneffei infection in southern China.

Methods: Between January 2018 and September 2020, we enrolled patients aged 18 years or older who were HIV-negative. Patients were further stratified into four main groups: patients with T. marneffei infection (group 1, n=42), including anti-IFN- $\gamma$ autoantibody-positive (group 1P) and anti-IFN- $y$ autoantibody-negative (group $1 \mathrm{~N}$ ) patients; patients with NTM infection (group 2, n=20); patients with pulmonary cryptococcosis (group 3, $n=20$ ); and healthy controls (group 4, $n=40$ ). Anti-IFN- $y$ autoantibodies were detected by ELISA. Clinical characteristics and clinical laboratory parameters were recorded.

Results: High anti-IFN-y autoantibody titers were found in both groups 1 and 2. Compared with anti-IFN- $\gamma$ autoantibody-negative patients with T. marneffei infection, anti-IFN-y autoantibody-positive patients did not have underlying respiratory disease; more frequently exhibited dissemination of systemic infections with severe pleural effusion; had higher WBC counts, C-reactive protein levels, erythrocyte sedimentation rates, and neutrophil and $\mathrm{CD}^{+} \mathrm{T}$ cell counts; had lower hemoglobin levels; and were more likely to have other intracellular pathogen infections. However, the anti-IFN-y autoantibody level did not correlate with the clinical disease course. Most of these patients had poor outcomes despite standardized antimicrobial therapy.

Conclusion: T. marneffei-infected patients with higher anti-IFN- $y$ autoantibody titers have more severe disease and complex clinical conditions.

\section{Introduction}

Immune deficiency, which is caused by anti-interferon- $\gamma$ autoantibodies (anti-IFN- $\gamma$ autoAbs), is an adult immune deficiency syndrome that was first described among patients with mycobacterial infection[1]. Patients have high titers of serum anti-IFN- $y$ autoAbs, which can inhibit signal transducer and activator of transcription 1 (STAT1) phosphorylation and interleukin-12 production, resulting in severe dysfunction of the Th1 response[1] and increased risk of infection by multiple intracellular pathogens, including nontuberculous Mycobacterium (NTM), Talaromyces marneffei (T. marneffei), Cryptococcus neoformans, and other intracellular pathogens[1-12]. Talaromycosis is a severe deep mycosis that mainly involves organs rich in monocyte-macrophages (i.e., the lungs, liver, and lymph nodes) and can be categorized into localized and disseminated disease. Disseminated disease is characterized by severe systemic symptoms and a high mortality rate[13].

T. marneffei infection has long been associated with acquired immunodeficiency syndrome caused by human immunodeficiency virus (HIV) infection[14]. In some regions, such as southern China, T. marneffei infection has historically been the major opportunistic infection associated with acquired 
immunodeficiency syndrome[15]. However, T. marneffei infection has been increasingly reported among non-HIV-infected patients with impaired cell-mediated immunity[16], and immune deficiency syndrome caused by anti-IFN- $\gamma$ autoAbs is an important risk factor[11, 12]. However, the impact of anti-IFN- $\gamma$ autoAbs on talaromycosis progression has not been clearly described.

In this study, we compared the clinical features and laboratory findings between T. marneffei-infected patients with and without high titers of serum anti-IFN-y autoAbs. We further evaluated the impact of antiIFN- $\gamma$ autoAbs on the dynamic disease course. Our findings provide more evidence for the diagnosis and treatment of non-HIV-infected patients with $T$. marneffei infection and will contribute to improved prognosis and a reduced mortality rate.

\section{Methods}

\section{Participants}

In this prospective, multicenter cohort study, patients with T. marneffei infection (group 1) were recruited between January 2018 and September 2020 from 7 academic centers [The First Affiliated Hospital of Guangzhou Medical University (Guangzhou); The Third Affiliated Hospital of Sun Yat-sen University (Guangzhou); The First Affiliated Hospital of Guangxi Medical University and The Affiliated Tumor Hospital of Guangxi Medical University (Nanning); The First Affiliated Hospital of Zhejiang University School of Medicine (Zhejiang); The Shengli Clinical Medical College of Fujian Medical University (Fuzhou) and The Eighth Affiliated Hospital of Sun Yat-Sen University (Shenzhen)]. The inclusion criteria were as follows: 1) No laboratory evidence of HIV infection; 2) Clinical and/or imaging manifestations of T. marneffei infection; 3) Microbiological or pathological findings identified from sputum, tracheal aspirate, bronchoalveolar lavage fluid, lung biopsy sample, pleural effusion, bone marrow smear, skin hydrolipidic film exudate or lymph node smear consistent with any of the following manifestations: a) visible detection of fungi (rounded or oval-shaped with an obvious transverse septum) by microscopy after Wright staining; $b$ ) isolation of pathogens from culture; or c) pathological examination revealing $T$. marneffei infection with pyogenic granulomatous changes, central necrosis, and massive monocytemacrophage infiltration[17].

Within the same time frame, we also recruited patients with cryptococcosis or NTM pulmonary disease and healthy subjects (as the control group). Patients in group 2 were positive for NTM infection, as confirmed by sputum smear and culture, and met the clinical and radiological criteria for NTM pulmonary disease[18]. Patients in group 3 were diagnosed with cryptococcosis, as confirmed by either the presence of Cryptococcus in histopathological or cytological specimens (including transbronchial lung biopsies and computed tomography-guided percutaneous lung biopsies)[19]. Healthy controls (group 4) with normal routine blood test findings and chest radiography were recruited from the health checkup center in The First Affiliated Hospital of Guangzhou Medical University.

We excluded study participants who were less than 18 years of age; had autoimmune disease, cancer, or immunodeficiency; or had received immunosuppressive medications within the previous 3 months. 
Participants with anti-IFN-y autoAb titers exceeding the 99th percentile of group 4 were classified as antiIFN-y autoAb-positive. We further divided group 1 into group 1P (anti-IFN-y autoAb-positive) and group 1N (anti-IFN-y autoAb-negative).

\section{Clinical assessment}

We measured the level of anti-IFN- $Y$ autoAbs and recorded the clinical characteristics and laboratory findings upon admission. For healthy controls, we documented age, sex, and race or ethnicity only. Patients with T. marneffei infection (group 1) were followed up at weeks 1 and 2 and months 1, 3, 6, 9 and 12 after antifungal treatment; at follow-up, the levels of anti-IFN-y autoAbs were detected, and the clinical conditions were recorded. The epidemiological and clinical characteristics, laboratory findings, treatment and outcome data were extracted into a standardized case report from the electronic medical records. If data were missing or clarification was needed, we then obtained the data by direct communication with the attending physicians and other health care providers. All case records were independently reviewed by two senior physicians (Z.M.C. and Y.L.).

\section{Determination of anti-IFN- $\mathrm{Y}$ autoAb titers}

Blood specimens were collected in $5 \mathrm{ml}$ anticoagulant tubes. Serum was separated by centrifugation at 3000 rpm for 10 minutes and diluted 16-fold. The serum anti-IFN- $y$ autoAb titers were determined by using an enzyme-linked immunosorbant assay kit (USCN Life Science, Inc., Wuhan, China) based on the instructions of the manufacturer. The anti-IFN- $\gamma$ autoAb titers were determined by comparing the optical density of the sample to the standard curve (detection range $3.12 \mathrm{ng} / \mathrm{ml}-200 \mathrm{ng} / \mathrm{ml}$ ).

\section{Statistical analysis}

Data were analyzed using IBM SPSS Statistics for Windows, version 23 (SPSS Inc, Chicago, Illinois), and a $P$-value $<0.05$ indicated statistical significance. Categorical data are presented as numbers and percentages, and continuous data are presented as medians and ranges or interquartile ranges (IQRs). Comparison of continuous data was performed using the Kruskal-Wallis test or Mann-Whitney test; Fisher's exact test was used to compare categorical variables. Comparison of the levels of anti-IFN-y autoAbs between each study group was performed using Student's t-test, the F-test and analysis of variance. Analyses of the associations between anti-IFN-y autoAb levels and factors of interest were carried out using linear correlation with the Pearson correlation coefficient. Associations between various possible risk factors and this clinical syndrome were calculated as odds ratios (ORs) and 95\% confidence intervals (Cls). Independent risk factors were identified by binary logistic regression to adjust for possible risk factors, defined as variables with $P<0.05$ in multivariable analysis.

\section{Results}

Of the 122 eligible participants, 42 had disseminated T. marneffei infection (group 1); 20 had NTM pulmonary disease (group 2); 20 had cryptococcosis (group 3); and 40 were healthy controls (group 4). The enrollment flow chart is shown in Fig. 1. 


\section{Baseline characteristics and anti-IFN- $\mathrm{Y}$ autoAb titers}

Sex distribution and age did not differ significantly among the groups (Table 1). The anti-IFN-y autoAb titers in both group 1 (median $661.33 \mathrm{ng} / \mathrm{ml}$, range 334.88-941.29 $\mathrm{ng} / \mathrm{ml}$ ) and group 2 (median 496.17 $\mathrm{ng} / \mathrm{ml}$, range $418.11-672.54 \mathrm{ng} / \mathrm{ml}$ ) were significantly higher than those in the healthy control group (median $353.97 \mathrm{ng} / \mathrm{ml}$, range $277.40-422.38 \mathrm{ng} / \mathrm{ml})(P<0.001)$. However, there was no significant difference between group 3 (median $346.24 \mathrm{ng} / \mathrm{ml}$, range $304.32-394.98 \mathrm{ng} / \mathrm{ml})$ and group $4(P=0.907$, Fig. 2). Compared with the proportion in group $3(n=2,10.0 \%)$, a significantly higher proportion of patients in group $1(n=21,50.0 \%)$ and group $2(n=7,35.0 \%)$ tested positive for anti-IFN-y autoAbs $(P<$ 0.01 , Table 1).

Table 1

Baseline characteristics of the participants

\begin{tabular}{|llllll|}
\hline Variable & Group 1 & Group 2 & Group 3 & Group 4 & $\begin{array}{c}\boldsymbol{P} \\
\text { value }\end{array}$ \\
\cline { 2 - 5 } & $\mathbf{( N = 4 2 )}$ & $\mathbf{( N = 2 0 )}$ & $\mathbf{( N = 2 0 )}$ & $\mathbf{( N = 4 0 )}$ & \\
\hline Age, years & $53(33,59)$ & $55(32,65)$ & $51(37,56)$ & $32(27,38)$ & 0.646 \\
\hline Male sex, no. (\%) & $27(64.3 \%)$ & $5(35.0 \%)$ & $8(40.0 \%)$ & $18(45.0 \%)$ & 0.094 \\
\hline $\begin{array}{l}\text { Anti-IFN-y antibody- } \\
\text { positive, }\end{array}$ & $22(52.4 \%)$ & $7(35.0 \%)$ & $2(10.0 \%)$ & 0 & 0.015 \\
no. (\%) & & & & & \\
\hline $\begin{array}{l}\text { Anti-IFN-y antibody } \\
\text { titer (ng/ml) }\end{array}$ & $\begin{array}{l}661.33 \\
\text { (334.88, }\end{array}$ & $\begin{array}{l}496.17 \\
(418.11,\end{array}$ & $\begin{array}{l}346.24 \\
(304.32,\end{array}$ & $\begin{array}{l}353.97 \\
(277.40,\end{array}$ & 0.001 \\
\hline
\end{tabular}

\section{Comparison of clinical features between group 1P and group $1 \mathrm{~N}$}

Based on the 99th percentile of the anti-IFN- $y$ autoAb titers in group 4, the cutoff for anti-IFN-y autoAb positivity was $594.49 \mathrm{ng} / \mathrm{ml}$ (Fig. 2). Twenty-two patients with T. marneffei infection were considered anti-IFN-y autoAb-positive (group 1P) (Table 2). No significant between-group differences were found when patients were stratified by age or sex. Significantly more patients with $T$. marneffei infection in group $1 \mathrm{~N}$ than in group $1 \mathrm{P}$ had underlying respiratory disease (including chronic obstructive pulmonary disease, bronchiectasis and asthma) $(P<0.05)$. In addition to the lungs, the lymph nodes were the most common organs involved in both groups. Compared with patients in group $1 \mathrm{~N}$, patients in group 1P were more likely to have bone and skin involvement $(P<0.05)$. There were no significant between-group differences in the proportions of patients with fever, cough or sputum production, hemoptysis, dyspnea, chest pain, osteodynia or arthralgia, wasting, or moist rales. However, compared with patients in group $1 \mathrm{~N}$, patients in group 1P were more likely to develop pleural effusion $(P<0.05)$. 
Table 2

Comparison of clinical characteristics between group 1P and group $1 \mathrm{~N}$ during the first visit

\begin{tabular}{|c|c|c|c|}
\hline \multirow[t]{2}{*}{ Variable } & \multirow{2}{*}{$\begin{array}{l}\text { Group 1P } \\
(\mathrm{N}=22)\end{array}$} & \multirow{2}{*}{$\begin{array}{l}\text { Group 1N } \\
(\mathrm{N}=20)\end{array}$} & \multirow{2}{*}{$\begin{array}{l}P \\
\text { value }\end{array}$} \\
\hline & & & \\
\hline Age, years & $52.0(34.8,58.0)$ & $54.5(29.0,63.8)$ & 0.734 \\
\hline Male sex, no. (\%) & $14(63.6 \%)$ & $13(65.0 \%)$ & 1.0 \\
\hline Anti-IFN-y antibody titer (ng/ml) & $\begin{array}{l}926.31(760.02 \\
2103.20)\end{array}$ & $\begin{array}{l}332.40 \\
(243.51,491.89)\end{array}$ & $\varangle 0.001$ \\
\hline Time from symptom onset to diagnosis & $149.5(57.2,272.3)$ & $98.5(22.3,154.5)$ & 0.107 \\
\hline Coexisting respiratory disease, no. (\%) & $3(13.6 \%)$ & $10(50.0 \%)$ & 0.019 \\
\hline Bronchiolitis & 0 & $4(20.0 \%)$ & 0.043 \\
\hline COPD & $2(9.1 \%)$ & $4(20.0 \%)$ & 0.400 \\
\hline COPD with bronchiectasis & 0 & $2(10.0 \%)$ & 0.221 \\
\hline Asthma & $1(4.5 \%)$ & 0 & 0.476 \\
\hline $\begin{array}{l}\text { Extrapulmonary organ involvement, no. } \\
(\%)\end{array}$ & $18(81.8 \%)$ & $11(55.0 \%)$ & 0.096 \\
\hline Skin & $10(45.5 \%)$ & $3(15.0 \%)$ & 0.047 \\
\hline Lymph node & $18(81.8 \%)$ & $11(55.0 \%)$ & 0.096 \\
\hline Liver & $2(9.1 \%)$ & $1(5.0 \%)$ & 1.000 \\
\hline Spleen & $2(9.1 \%)$ & 0 & 0.489 \\
\hline Bone & $9(40.9 \%)$ & $1(5.0 \%)$ & 0.010 \\
\hline \multicolumn{4}{|l|}{ Symptoms, no. (\%) } \\
\hline Fever & $12(54.5 \%)$ & $6(30.0 \%)$ & 0.131 \\
\hline Cough & $17(77.3 \%)$ & $17(85.0 \%)$ & 0.700 \\
\hline Sputum production & $14(63.6 \%)$ & $15(75.0 \%)$ & 0.514 \\
\hline Hemoptysis & $4(18.2 \%)$ & $3(15.0 \%)$ & 1.0 \\
\hline Dyspnea & $6(27.3 \%)$ & $3(15 \%)$ & 0.460 \\
\hline Chest pain & $9(40.9 \%)$ & $6(30.0 \%)$ & 0.531 \\
\hline \multicolumn{4}{|c|}{ COPD = chronic obstructive pulmonary disease } \\
\hline \multicolumn{4}{|c|}{ Group 1P = anti-IFN- $\gamma$ autoantibody-positive group } \\
\hline Group $1 \mathrm{~N}=$ anti-IFN-y autoantibody-nega & ve group & & \\
\hline
\end{tabular}




\begin{tabular}{|llll|}
\hline Variable & Group 1P & Group 1N & $P$ \\
\cline { 2 - 3 } & $\mathbf{( N = 2 2 )}$ & $\mathbf{( N = 2 0 )}$ & value \\
\hline Osteodynia/Arthralgia & $7(31.8 \%)$ & $3(15.0 \%)$ & 0.284 \\
\hline Wasting & $13(59.0 \%)$ & $10(50.0 \%)$ & 0.757 \\
\hline Moist rales & $6(27.3 \%)$ & $8(40.0 \%)$ & 0.515 \\
\hline Pleural effusion & $13(59.1 \%)$ & $3(15.0 \%)$ & 0.005 \\
\hline COPD = chronic obstructive pulmonary disease & & \\
\hline Group 1P = anti-IFN-y autoantibody-positive group & & \\
\hline Group 1N = anti-IFN-y autoantibody-negative group & & \\
\hline
\end{tabular}

The laboratory findings are shown in Table 3. Patients in group 1P had markedly higher leukocyte counts, neutrophil counts, eosinophil counts, erythrocyte sedimentation rates and C-reactive protein levels and lower hemoglobin levels than patients in group $1 \mathrm{~N}(P<0.05)$. Immunoglobulin levels were available for 32 patients. Patients in group 1P were more likely to have higher IgG antibody levels than those in group $1 \mathrm{~N}$. $T$ cell counts were available for 25 patients, with median $\mathrm{CD}^{+} \mathrm{T}$ cell and $\mathrm{CD} 8^{+} \mathrm{T}$ cell counts of 1425.0 cells/ $\mu \mathrm{l}$ and 631.0 cells $/ \mu \mathrm{l}$, respectively, in group 1P. These counts were significantly higher than those in group $1 \mathrm{~N}$. Modest between-group differences were identified when patients were stratified by the percentage of neutrophils and the platelet count. 
Table 3

Comparison of laboratory findings between group $1 \mathrm{P}$ and group $1 \mathrm{~N}$ during the first visit

\begin{tabular}{|c|c|c|c|}
\hline \multirow[t]{2}{*}{ Variable } & Group 1P & Group 1N & \multirow[t]{2}{*}{$P$ value } \\
\hline & $(\mathrm{N}=22)$ & $(N=20)$ & \\
\hline White cell count $\left(* 10^{9}\right.$ cells/L) & $13.4(9.3,18.0)$ & $7.7(5.8,12.0)$ & 0.012 \\
\hline $\begin{array}{l}\text { Absolute neutrophil count } \\
\left({ }^{\star} 10^{9} \text { cells } / \mathrm{L}\right)\end{array}$ & $10.7(6.9,13.3)$ & $5.1(3.6,11.4)$ & 0.019 \\
\hline Neutrophil ratio (neut \%) & $0.76(0.7,0.9)$ & $0.7(0.6,0.8)$ & 0.120 \\
\hline Eosinophil count $\left({ }^{*} 10^{9}\right.$ cells/L) & $0.4(0.1,0.6)$ & $0.1(0.1,0.3)$ & 0.030 \\
\hline Hemoglobin $(\mathrm{g} / \mathrm{L})$ & $89.7(69.0,123.8)$ & $111.0(93.8,129.8)$ & 0.049 \\
\hline Platelet count $\left(* 10^{9}\right.$ cells $\left./ \mathrm{L}\right)$ & $310.5(226.2,485.7)$ & $312.0(189.0,408.0)$ & 0.569 \\
\hline Erythrocyte sedimentation rate $(\mathrm{mm} / \mathrm{h})$ * & $98.0(72.0,102.0)$ & $52.0(15.9,88.0)$ & 0.008 \\
\hline C-reactive protein $(\mathrm{mg} / \mathrm{dL}) \dagger$ & $7.7(3.3,15.7)$ & $72.5(14.9,137.2)$ & 0.002 \\
\hline \multicolumn{4}{|l|}{ Immunoglobulin $\ddagger$} \\
\hline $\lg G(g / L)$ & $28.7(17.5,34.0)$ & $17.7(13.7,25.8)$ & 0.026 \\
\hline $\lg A(g / L)$ & $1.1(0.8,1.5)$ & $1.2(0.9,2.2)$ & 0.400 \\
\hline $\lg M(g / L)$ & $2.6(1.5,2.8)$ & $2.2(1.5,2.9)$ & 0.880 \\
\hline \multicolumn{4}{|l|}{ T cell count $\S$} \\
\hline CD3 $+\mathrm{T}$ cell count $($ cells $/ \mu \mathrm{l})$ & $1425.0(109.1,1945.0)$ & $830.5(355.5,1302.3)$ & 0.011 \\
\hline CD4 $+\mathrm{T}$ cell count $($ cells $/ \mu \mathrm{l})$ & $685.0(419.0,965.5)$ & $433.0(111.3,844.5)$ & 0.247 \\
\hline CD8 $+\mathrm{T}$ cell count $($ cells $/ \mu \mathrm{l})$ & $631.0(499.0,1132.0)$ & $333.5(151.0,467.0)$ & $₫ 0.001$ \\
\hline \multicolumn{4}{|c|}{ *Erythrocyte sedimentation rate data were missing for 8 patients $(19 \%)$. } \\
\hline \multicolumn{4}{|c|}{ tC-reactive protein data were missing for 12 patients (28.5\%). } \\
\hline \multicolumn{4}{|c|}{ ‡Immunoglobulin data were missing for 10 patients $(23.8 \%)$. } \\
\hline \multicolumn{4}{|c|}{$\S T$ cell count data were missing for 17 patients $(40.5 \%)$. } \\
\hline \multicolumn{4}{|c|}{ Group 1P = anti-IFN-y autoantibody-positive group } \\
\hline Group $1 \mathrm{~N}=$ anti-IFN- $y$ autoantibody-nega & ve group & & \\
\hline
\end{tabular}


Moreover, the white blood cell count and erythrocyte sedimentation rate correlated significantly with the levels of anti-IFN- $\gamma$ autoAbs in group 1 (Fig. 3A-B). In addition, there was an apparent correlation between neutrophils and anti-IFN-y autoAbs. (Fig. 3C). Univariate logistic regression analysis of patients in group 1 showed that underlying respiratory disease $(P=0.031)$ and pleural effusion $(P=0.018)$ were independent factors associated with the appearance of anti-IFN- $\gamma$ autoAb positivity (Table 4).

Table 4

Multivariate logistic regression analysis of factors associated with the appearance of anti-IFN-y autoantibody positivity

\begin{tabular}{|c|c|c|c|c|}
\hline Variable & $\begin{array}{l}\text { Univariable OR } \\
(95 \% \mathrm{Cl})\end{array}$ & $\begin{array}{l}P \\
\text { value }\end{array}$ & $\begin{array}{l}\text { Multivariable } \\
\text { OR }(95 \% \mathrm{Cl})\end{array}$ & $\begin{array}{l}P \\
\text { value }\end{array}$ \\
\hline White-cell count $\left({ }^{\star} 10^{9}\right.$ cells $/ \mathrm{L}$ ) & $\begin{array}{l}1.134(1.007 \\
1.277)\end{array}$ & 0.038 & $1.035(0.906,1.183)$ & 0.610 \\
\hline Hemoglobin $(\mathrm{g} / \mathrm{L})$ & $\begin{array}{l}0.973(0.947 \\
1.001)\end{array}$ & 0.057 & $0.985(0.948,1.024)$ & 0.454 \\
\hline Coexisting respiratory disease & $\begin{array}{l}0.158(0.035 \\
0.708)\end{array}$ & 0.016 & $0.094(0.011,0.809)$ & 0.031 \\
\hline Pleural effusion & $\begin{array}{l}8.185(1.839, \\
36.424)\end{array}$ & 0.006 & $\begin{array}{l}11.162(1.517, \\
82.164)\end{array}$ & 0.018 \\
\hline $\begin{array}{l}\text { Extrapulmonary organ } \\
\text { involvement }\end{array}$ & $\begin{array}{l}3.682(0.911 \\
14.876)\end{array}$ & 0.067 & $0.469(0.046,4.834)$ & 0.525 \\
\hline
\end{tabular}

\section{Clinical courses and outcomes of patients with T. marneffei infection}

Of the 42 patients, $12(55.0 \%)$ in group 1P and $5(25.0 \%)$ in group $1 \mathrm{~N}(P<0.05)$ were coinfected with other intracellular pathogens, including NTM $(n=4 ; 18.2 \%)$, Mycobacterium tuberculosis $(n=4 ; 18.2 \%)$, cytomegalovirus $(n=3 ; 13.6 \%)$, Epstein-Barr virus $(n=3 ; 13.6 \%)$, Candida albicans $(n=1 ; 4.5 \%)$, Cryptococcus spp. $(n=1 ; 4.5 \%)$, and varicella zoster virus $(n=1 ; 4.5 \%)$ (Fig. 4).

In addition, data were available for 12 patients in group $1 \mathrm{P}$ and 6 patients in group $1 \mathrm{~N}$ during the longitudinal follow-up. No marked change was observed in autoAb titers despite disease progression (Fig. 5A). Moreover, despite long-term intensive treatment, patients in group 1P had a worse prognosis than patients in group $1 \mathrm{~N}$ : in group 1P, 2 patients died within the first 30 postoperative days (premature mortality) because of severe disease, and 6 patients had persistent T. marneffei infection with a poor response after treatment. Furthermore, one patient experienced clinical recurrence at 12 months (Fig. 5B).

\section{Discussion}


In this study, we confirmed that anti-IFN-y autoAbs are an important risk factor for T. marneffei infection among non-HIV-infected patients. Most patients who were anti-IFN-y autoAb-positive did not have any underlying respiratory disease and frequently had systemic dissemination with major pleural effusion. In addition, the leukocyte count and the levels of C-reactive protein and other inflammatory markers in these patients were significantly higher than those in anti-IFN-y autoAb-negative patients. Despite the progression of T. marneffei infection, the anti-IFN- $y$ autoAb titer did not decrease after targeted treatment, and most patients had a poor outcome (such as death or recurrence of infection).

Anti-IFN-y autoAbs have previously been shown to be an important risk factor for NTM and T. marneffei infections. Our data also supported this important finding. A large number of anti-IFN-y autoAb-positive patients were found in both group 1 and group 2. This might be related to the high prevalence of anti-IFNY autoAb-associated HLA class II DRB1*16:02 and DQB1*05:02 alleles in the Asian population[20, 21]. Both Guangdong and Guangxi provinces are located in southern China, where NTM and T. marneffei are endemic due to the humid climate. In group 3, only two patients were anti-IFN-y autoAb-positive, possibly because cryptococcal infection is associated with other anti-cytokine antibodies. A recent study also confirmed the link between the presence of neutralizing anti-granulocyte macrophage colony stimulating factor autoAbs and cerebral cryptococcosis, particularly that caused by $C$. gattii infection[22].

Since the 1990s, an increasing number of patients with $T$. marneffei infection have been reported among non-HIV-infected patients with impaired cell-mediated immunity. The comorbidities included primary adult-onset immunodeficiency due to anti-IFN- $y$ autoAbs and secondary immunocompromise, including that resulting from autoimmune disease or the use of immunosuppressive drugs such as novel anticancer targeted therapies and kinase inhibitors[16], but infections have been found even in patients with normal immunity[23]. The pathogenesis of anti-IFN-y autoAb-positive patients was different from that of anti-IFN- $y$ autoAb-negative patients who had normal immunity and suffered from chronic lung diseases (such as COPD, bronchiectasis or asthma). Chronic lung diseases can lead to lung structural damage in various ways, resulting in impaired natural immune function and thereby changing the microenvironment that offers a niche for respiratory microorganisms. Furthermore, dysmicrobiosis might have increased the susceptibility of the hosts to T. marneffei infection[24, 25]. As a result, the lungs were the dominant organs involved, whereas anti-IFN-y autoAb-positive patients were more likely to develop systemic dissemination of T. marneffei infection and pleural effusion[8]. Most patients with T. marneffei infection had pleural effusion characterized by yellowish exudates, with marked elevation of protein levels and nucleated cell counts[26]. Multiple organs might also be involved, especially the bone and skin, which might readily predispose patients to the development of Sweet syndrome[27].

Patients who tested positive for anti-IFN- $y$ autoAbs also had more significantly elevated inflammatory responses characterized by elevated leukocyte and neutrophil counts, erythrocyte sedimentation rates and C-reactive protein levels, markers indicating more exuberant infections in patients with anti-IFN-y autoAbs. Neutrophils play an important role in the development of innate immunity. Neutrophils are the frontline barrier for eradicating the invasion of microbial pathogens and have powerful phagocytic capacity. In addition, neutrophils have been implicated in the production of the chemokine

Page $11 / 23$ 
myeloperoxidase[28]. Neutrophil-derived IL-17A[29] also induces the release of IFN- $\gamma$, which promotes the antibacterial activity of macrophages[30]. We also observed a notable bone marrow response in this patient population, which was more prone to developing anemia[10] and leukocytosis[11]. A significant increase in $\mathrm{CD}^{+} \mathrm{T}$ cells was observed in anti-IFN- $\gamma$ autoAb-positive patients. IFN- $\gamma$ is indispensable for fighting infections because of its ability to regulate various protective functions and sustain the activity of both $\mathrm{CD} 4^{+}$and $\mathrm{CD} 8^{+} \mathrm{T}$ cells[31]. Conversely, IFN-y produced by $\mathrm{CD} 8^{+} \mathrm{T}$ cells promotes the expression of major histocompatibility complex molecules on the surface of target cells to enhance antigen presentation and enhances the ability of macrophages and dendritic cells to phagocytose pathogens[32]. We speculate that the autoAbs might have affected the normal function of IFN- $\gamma$, leading to compensatory proliferation of these immune cells.

The patients were prospectively followed for up to 12 months, thus allowing us to estimate the correlation between the autoAb titer and disease progression. However, the anti-IFN- $\gamma$ autoAb level did not correlate significantly with the clinical course, which was consistent with the findings from a previous study[33]. In addition, anti-IFN- $y$ autoAb-positive patients were more likely to be coinfected with other intracellular pathogens, especially NTM[34, 35]. Despite the initiation of standardized antimicrobial therapy, the patients' conditions did not improve, and some deteriorated even further. There is no well-established standard therapy to reduce the titer of anti-IFN-y autoAbs. However, one study reported a significant improvement in clinical symptoms after plasma exchange therapy[10]. Supplementation of IFN- $\gamma$ recombinant protein[36] and B cell depletion with an anti-CD20 antibody[37,38] have also been successfully used as adjuvant therapies in combination with antimicrobial therapy in a small number of patients. Prospective randomized clinical trials are needed to determine the therapeutic efficiency of these strategies.

Some limitations of our study need to be acknowledged. First, our sample size was relatively small, and therefore, selection bias might have affected the interpretation of our data. Second, for some patients, documentation of the laboratory findings during the longitudinal follow-up was incomplete, which hampered assessment of associations with the therapeutic response. Moreover, this was an observational cohort study with a limited duration of follow-up, and additional immunological experiments are needed to further explore the underlying mechanism.

\section{Conclusion}

We outlined the clinical characteristics of $T$. marneffei-infected patients with immunodeficiency due to the presence of anti-IFN-y autoAbs. These patients were more likely than anti-IFN-y autoAb-negative patients to have systemic dissemination of infection and heightened inflammatory responses. More studies are needed to explore how to reduce the production of autoAbs, which might help to manage T. marneffei infection in patients with anti-IFN-y autoAbs.

\section{Abbreviations}


anti-IFN- $\gamma$ autoAbs $=$ anti-interferon- $y$ autoantibodies

NTM =nontuberculous Mycobacterium

marneffei $=$ Talaromyces marneffei

HIV=human immunodeficiency virus

IQRs =interquartile ranges

$\mathrm{COPD}=$ chronic obstructive pulmonary disease

Group 1P= anti-IFN-y autoantibody-positive group

Group $1 \mathrm{~N}=$ anti-IFN- $\gamma$ autoantibody-negative group

ORs $=$ odds ratios

Cls= confidence intervals

\section{Declarations}

\section{Ethics approval and consent to participate:}

The study was carried out in accordance with the Declaration of Helsinki. The study was approved by the Ethics Committee of the First Affiliated Hospital of Guangzhou Medical University (reference number 2019026). All methods were carried out in accordance with relevant guidelines and regulations. All included patients gave their oral and written informed consent.

\section{Consent for publication}

Not applicable.

\section{Availability of data and materials}

Not applicable.

\section{Competing interests:}

The authors report no conflicts of interest.

\section{Funding:}

This work was funded by the open fund of State Key Laboratory of Respiratory Diseases (SKLRD-OP201913); The independent fund of State Key Laboratory of Respiratory Diseases (SKLRD-Z-202019); The Guangzhou Institute of Respiratory Health Open Project (2019GIRHZ06). 


\section{Authors' contributions:}

All authors fulfilled the contribution requirements as per the International Committee of Medical Journal Editors role of authors and contributor guidelines. Chen ZM, Li ZT, Zhang JQ and Ye F conceived of and designed the study. Chen ZM, Guan WJ and Ye F carried out the analyses and wrote the first draft of the manuscript. Zhan YQ, Qiu Y, Lei ZY, Li SQ, Zhou H, Lin S, Zeng W and Liu J carried out the patient's recruitment and clinical sample collection. Chen ZM and Li Z contributed to the handling and testing of samples. Chen ZM and Lin Y contributed to the collection of data from the electronic medical records. All authors contributed to data acquisition, data analysis, or data interpretation and reviewed and approved the final version of the manuscript.

\section{Acknowledgments:}

We thank the patient; the nurses and clinical staffs who are providing care for the patient; staffs at the respiratory medicine department of hospital; staffs at the clinical lab of hospital; technical staffs of the department of State Key Laboratory of Respiratory Disease for excellent assistance. Furthermore, we would also like to thank AJE team for polishing the English language of this manuscript.

\section{References}

1. Doffinger R, Helbert MR, Barcenas-Morales $G$, et al. Autoantibodies to interferon-gamma in a patient with selective susceptibility to mycobacterial infection and organ-specific autoimmunity. Clin Infect Dis 2004;38:e10-4. https://doi.org/10.1086/380453.

2. Browne SK, Burbelo PD, Chetchotisakd P, et al. Adult-Onset Immunodeficiency in Thailand and Taiwan. New England Journal of Medicine 2012;367:725-734. https://doi.org/10.1056/NEJMoa1111160.

3. Xie YL, Rosen LB, Sereti I, et al. Severe Paradoxical Reaction During Treatment of Disseminated Tuberculosis in a Patient With Neutralizing Anti-IFNgamma Autoantibodies. Clin Infect Dis 2016;62:770-773. https://doi.org/10.1093/cid/civ995.

4. Yerramilli A, Huang G, Griffin D, et al. Disseminated Nontuberculous Mycobacterial Infection Associated With Acquired Immunodeficiency Due to Anti-Interferon gamma Autoantibodies. Open Forum Infect Dis 2019;6:ofz131. https://doi.org/10.1093/ofid/ofz131.

5. van de Vosse E, Hoeve MA, Ottenhoff TH. Human genetics of intracellular infectious diseases: molecular and cellular immunity against mycobacteria and salmonellae. The Lancet Infectious Diseases 2004;4:739-749. https://doi.org/10.1016/S1473-3099(04)01203-4.

6. Höflich C, Sabat R, Rosseau S, et al. Naturally occurring anti-IFN-y autoantibody and severe infections with Mycobacterium cheloneae and Burkholderia cocovenenans. Blood 2004;103:673-675. https://doi.org/10.1182/blood-2003-04-1065.

7. Tang BSF, Chan JFW, Chen M, et al. Disseminated Penicilliosis, Recurrent Bacteremic Nontyphoidal Salmonellosis, and Burkholderiosis Associated with Acquired Immunodeficiency Due to 
Autoantibody against Gamma Interferon. Clinical and Vaccine Immunology 2010;17:1132-1138. https://doi.org/10.1128/CVI.00053-10.

8. Wongkulab P, Wipasa J, Chaiwarith R and Supparatpinyo K. Autoantibody to interferon-gamma associated with adult-onset immunodeficiency in non-HIV individuals in Northern Thailand. PLoS One 2013;8:e76371. https://doi.org/10.1371/journal.pone.0076371.

9. Phoompoung P, Ankasekwinai N, Pithukpakorn M, et al. Factors associated with acquired Anti IFN- $Y$ autoantibody in patients with nontuberculous mycobacterial infection. PLOS ONE 2017;12:e0176342. https://doi.org/10.1371/journal.pone.0176342.

10. Angkasekwinai N, Suputtamongkol Y, Phoompoung P, et al. Clinical outcome and laboratory markers for predicting disease activity in patients with disseminated opportunistic infections associated with anti-interferon-y autoantibodies. PLOS ONE 2019;14:e0215581. https://doi.org/10.1371/journal.pone.0215581.

11. Zeng W, Qiu Y, Tang S, Zhang J, Pan M and Zhong X. Characterization of Anti-Interferon-gamma Antibodies in HIV-Negative Patients Infected With Disseminated Talaromyces marneffei and Cryptococcosis. Open Forum Infect Dis 2019;6:ofz208. https://doi.org/10.1093/ofid/ofz208.

12. Guo J, Ning XQ, Ding JY, et al. Anti-IFN-gamma autoantibodies underlie disseminated Talaromyces marneffei infections. J Exp Med 2020;217. https://doi.org/10.1084/jem.20190502. https://doi.org/10.1084/jem.20190502.

13. Chitasombat M, Supparatpinyo K. Penicillium marneffei Infection in Immunocompromised Host. Current Fungal Infection Reports 2013;7:44-50. https://doi.org/10.1007/s12281-012-0119-5.

14. Vanittanakom N, Cooper CJ, Fisher MC and Sirisanthana T. Penicillium marneffei infection and recent advances in the epidemiology and molecular biology aspects. Clin Microbiol Rev 2006;19:95110. https://doi.org/10.1128/CMR.19.1.95-110.2006.

15. Wong S, Siau H, Yuen KY. Penicilliosis marneffei-West meets East. J Med Microbiol 1999;48:973975. https://doi.org/10.1099/00222615-48-11-973.

16. Chan JF, Lau SK, Yuen KY and Woo PC. Talaromyces (Penicillium) marneffei infection in non-HIVinfected patients. Emerg Microbes Infect 2016;5:e19. https://doi.org/10.1038/emi.2016.18.

17. Kaplan JE, Benson C, Holmes KK, Brooks JT, Pau A and Masur H. Guidelines for prevention and treatment of opportunistic infections in HIV-infected adults and adolescents: recommendations from CDC, the National Institutes of Health, and the HIV Medicine Association of the Infectious Diseases Society of America. MMWR Recomm Rep 2009;58:1-207; quiz CE1-4. https://www.cdc.gov/mmwr/preview/mmwrhtml/rr5804a1.htm

18. Griffith DE, Aksamit T, Brown-Elliott BA, et al. An official ATS/IDSA statement: diagnosis, treatment, and prevention of nontuberculous mycobacterial diseases. Am J Respir Crit Care Med 2007;175:367416. https://doi.org/10.1164/rccm.200604-571ST.

19. De Pauw B, Walsh TJ, Donnelly JP, et al. Revised definitions of invasive fungal disease from the European Organization for Research and Treatment of Cancer/Invasive Fungal Infections Cooperative Group and the National Institute of Allergy and Infectious Diseases Mycoses Study 
Group (EORTC/MSG) Consensus Group. Clin Infect Dis 2008;46:1813-21.

https://doi.org/10.1086/588660.

20. Pithukpakorn M, Roothumnong E, Angkasekwinai N, et al. HLA-DRB1 and HLA-DQB1 Are Associated with Adult-Onset Immunodeficiency with Acquired Anti-Interferon-Gamma Autoantibodies. PLOS ONE 2015;10:e0128481. https://doi.org/10.1371/journal.pone.0128481.

21. Ku CL, Lin $\mathrm{CH}$, Chang SW, et al. Anti-IFN-gamma autoantibodies are strongly associated with HLA$D R^{\star}$ 15:02/16:02 and HLA-DQ*05:01/05:02 across Southeast Asia. J Allergy Clin Immunol 2016;137:945-8.e8. https://doi.org/10.1016/j.jaci.2015.09.018.

22. Barcenas-Morales G, Cortes-Acevedo P, Doffinger R. Anticytokine autoantibodies leading to infection: early recognition, diagnosis and treatment options. Curr Opin Infect Dis 2019;32:330-336. https://doi.org/10.1097/QC0.0000000000000561.

23. Lee PP, Chan KW, Lee TL, et al. Penicilliosis in children without HIV infection-are they immunodeficient? Clin Infect Dis 2012;54:e8-e19. https://doi.org/10.1093/cid/cir754.

24. O'Dwyer DN, Dickson RP, Moore BB. The Lung Microbiome, Immunity, and the Pathogenesis of Chronic Lung Disease. J Immunol 2016;196:4839-47. https://doi.org/10.4049/jimmunol.1600279.

25. Dickson RP, Martinez FJ, Huffnagle GB. The role of the microbiome in exacerbations of chronic lung diseases. Lancet 2014;384:691-702. https://doi.org/10.1016/S0140-6736(14)61136-3.

26. Qiu Y, Zeng W, Zhang H, Zhong X, Tang S and Zhang J. Comparison of pleural effusion features and biomarkers between talaromycosis and tuberculosis in non-human immunodeficiency virus-infected patients. BMC Infect Dis 2019;19:745. https://doi.org/10.1186/s12879-019-4376-6.

27. Chan JF, Trendell-Smith NJ, Chan JC, et al. Reactive and infective dermatoses associated with adultonset immunodeficiency due to anti-interferon-gamma autoantibody: Sweet's syndrome and beyond. Dermatology 2013;226:157-66. https://doi.org/10.1159/000347112.

28. Yamaguchi R, Kawata J, Yamamoto T, et al. Mechanism of interferon-gamma production by monocytes stimulated with myeloperoxidase and neutrophil extracellular traps. Blood Cells Mol Dis 2015;55:127-33. https://doi.org/10.1016/j.bcmd.2015.05.012.

29. Cai S, Batra S, Langohr I, Iwakura Y and Jeyaseelan S. IFN-gamma induction by neutrophil-derived IL17A homodimer augments pulmonary antibacterial defense. Mucosal Immunol 2016;9:718-29. https://doi.org/10.1038/mi.2015.95.

30. Wang G, Lin A, Han Q, Zhao H, Tian Z and Zhang J. IFN-gamma protects from apoptotic neutrophilmediated tissue injury during acute Listeria monocytogenes infection. Eur J Immunol 2018;48:14701480. https://doi.org/10.1002/eji.201847491.

31. Kak G, Raza M, Tiwari BK. Interferon-gamma (IFN-y): Exploring its implications in infectious diseases. Biomolecular Concepts 2018;9:64-79. https://doi.org/10.1515/bmc-2018-0007.

32. Andersen MH, Schrama D, Thor SP and Becker JC. Cytotoxic T cells. J Invest Dermatol 2006;126:3241. https://doi.org/10.1038/sj.jid.5700001.

33. Tham EH, Huang $\mathrm{CH}$, Soh JY, et al. Neutralizing Anti-Interferon-Gamma Autoantibody Levels May Not Correlate With Clinical Course of Disease. Clin Infect Dis 2016;63:572-3. 
https://doi.org/10.1093/cid/ciw351.

34. Zhang J, Huang X, Zhang X, et al. Coinfection of disseminated Talaromyces marneffei and Mycobacteria kansasii in a patient with papillary thyroid cancer: A case report. Medicine (Baltimore) 2017;96:e9072. https://doi.org/10.1097/MD.0000000000009072.

35. Su SS, Zhang SN, Ye JR, et al. Disseminated Talaromyces marneffei And Mycobacterium avium Infection Accompanied Sweet's Syndrome In A Patient With Anti-Interferon-gamma Autoantibodies: A Case Report. Infect Drug Resist 2019;12:3189-3195. https://doi.org/10.2147/IDR.S218836.

36. Lin $\mathrm{CH}$, Chi $\mathrm{CY}$, Shih HP, et al. Identification of a major epitope by anti-interferon-gamma autoantibodies in patients with mycobacterial disease. Nat Med 2016;22:994-1001. https://doi.org/10.1038/nm.4158.

37. Browne SK, Zaman R, Sampaio EP, et al. Anti-CD20 (rituximab) therapy for anti-IFN-gamma autoantibody-associated nontuberculous mycobacterial infection. Blood 2012;119:3933-9. https://doi.org/10.1182/blood-2011-12-395707.

38. Hong GH, Ortega-Villa AM, Hunsberger S, et al. Natural History and Evolution of Anti-Interferongamma Autoantibody-Associated Immunodeficiency Syndrome in Thailand and the United States. Clin Infect Dis 2020;71:53-62. https://doi.org/10.1093/cid/ciz786.

\section{Figures}




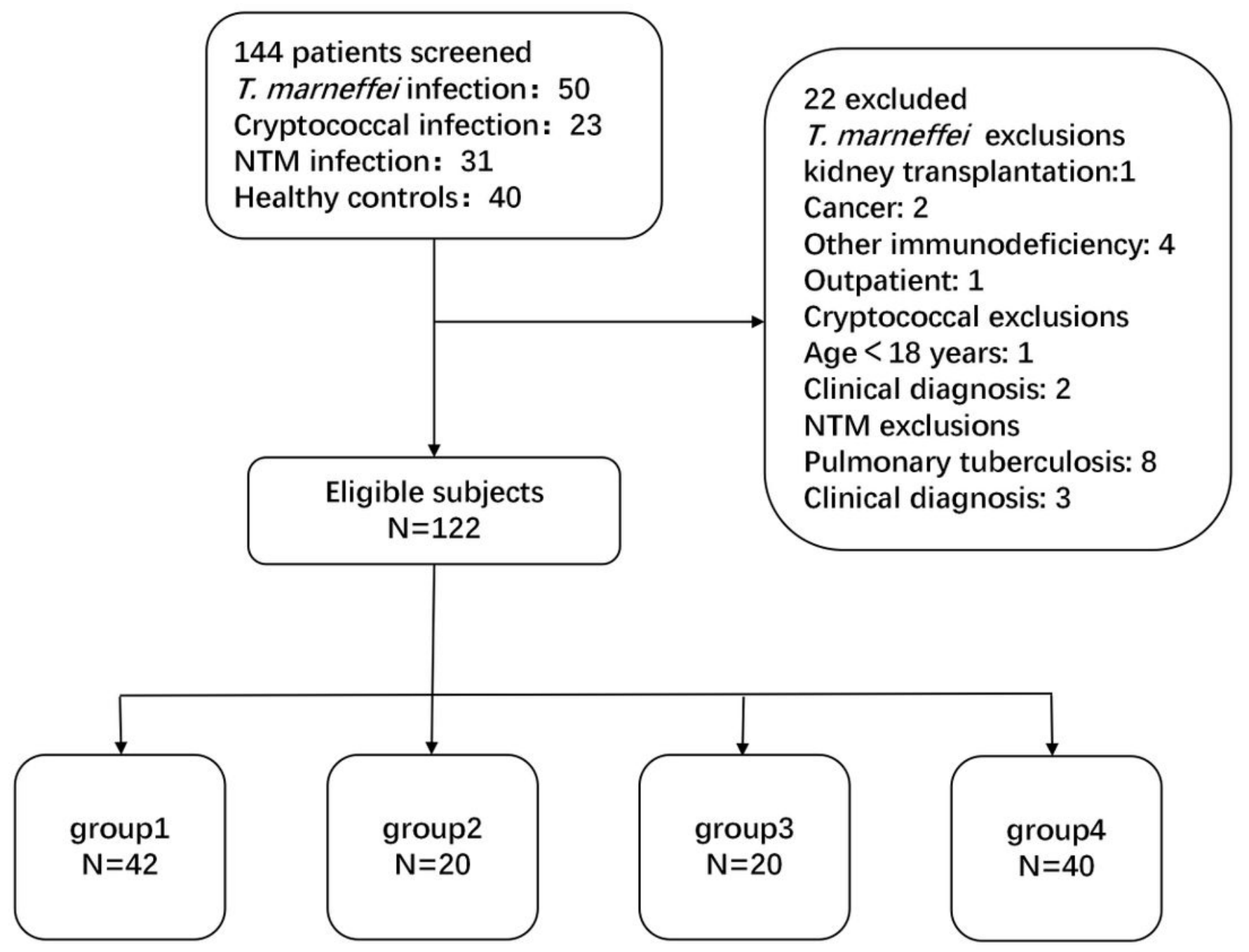

Figure 1

Flow chart of patient recruitment. NTM = Nontuberculous Mycobacterium 


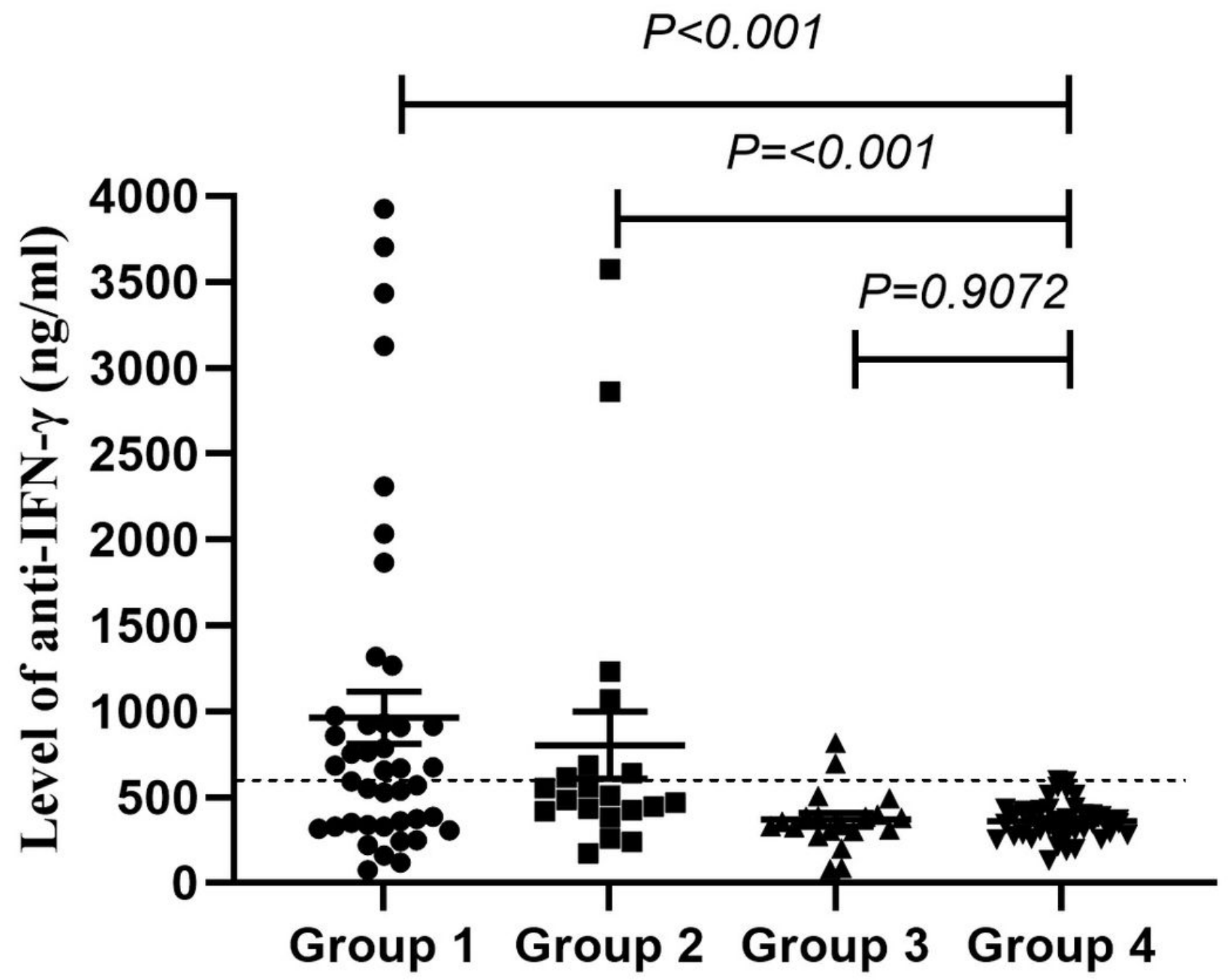

Figure 2

Levels of anti-IFN- $\gamma$ autoAbs in 118 patients upon hospital admission Each symbol represents an individual study participant. The dashed line indicates the estimated 99th percentile for the control group (group 4). 
A

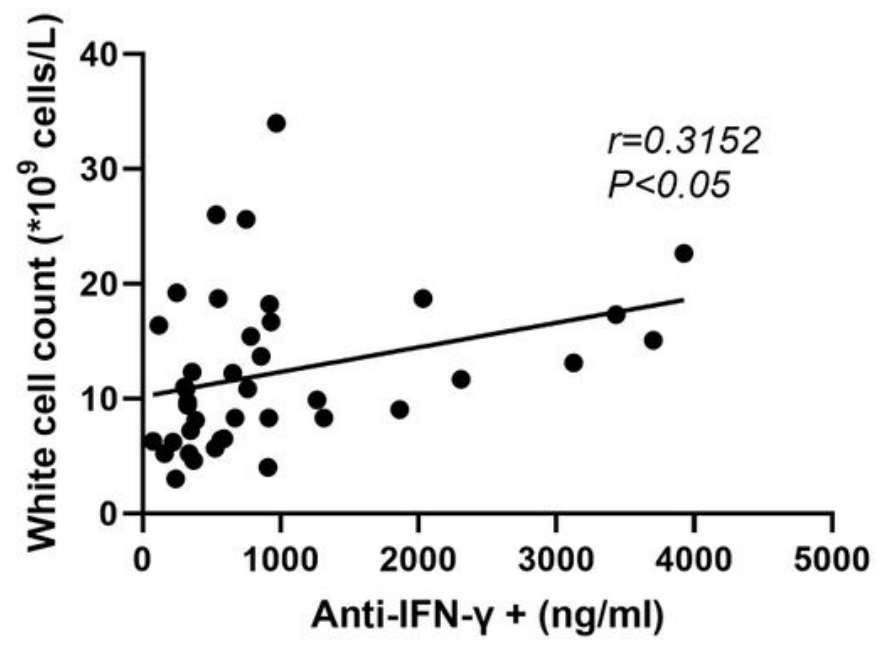

B

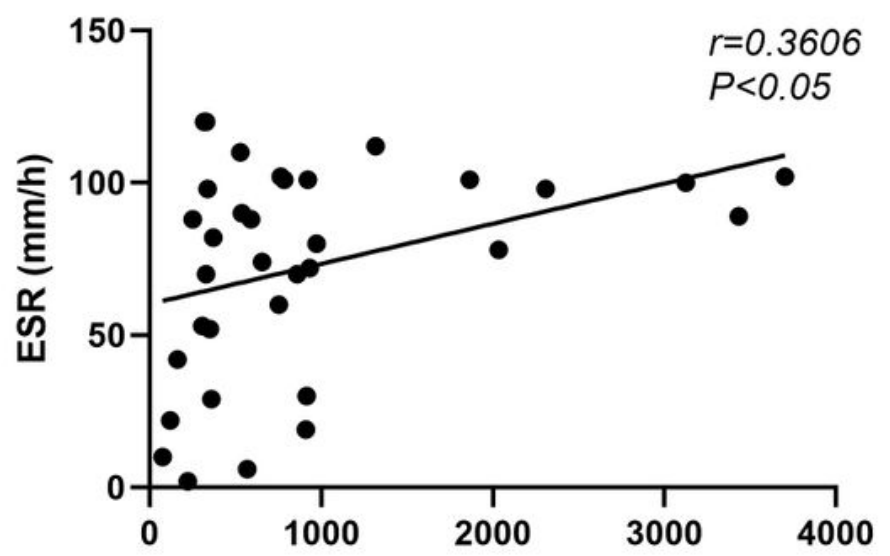

C

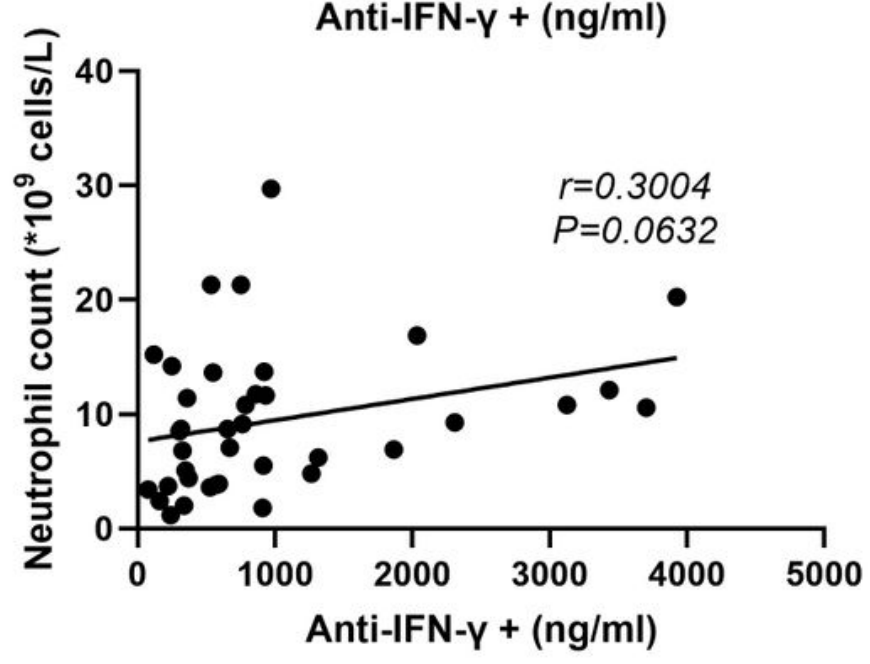

Figure 3

Pearson correlation analysis of serum anti-IFN-y autoAbs and inflammatory markers in group 1 Shown are the white-cell count, erythrocyte sedimentation rate, and absolute neutrophil count. 


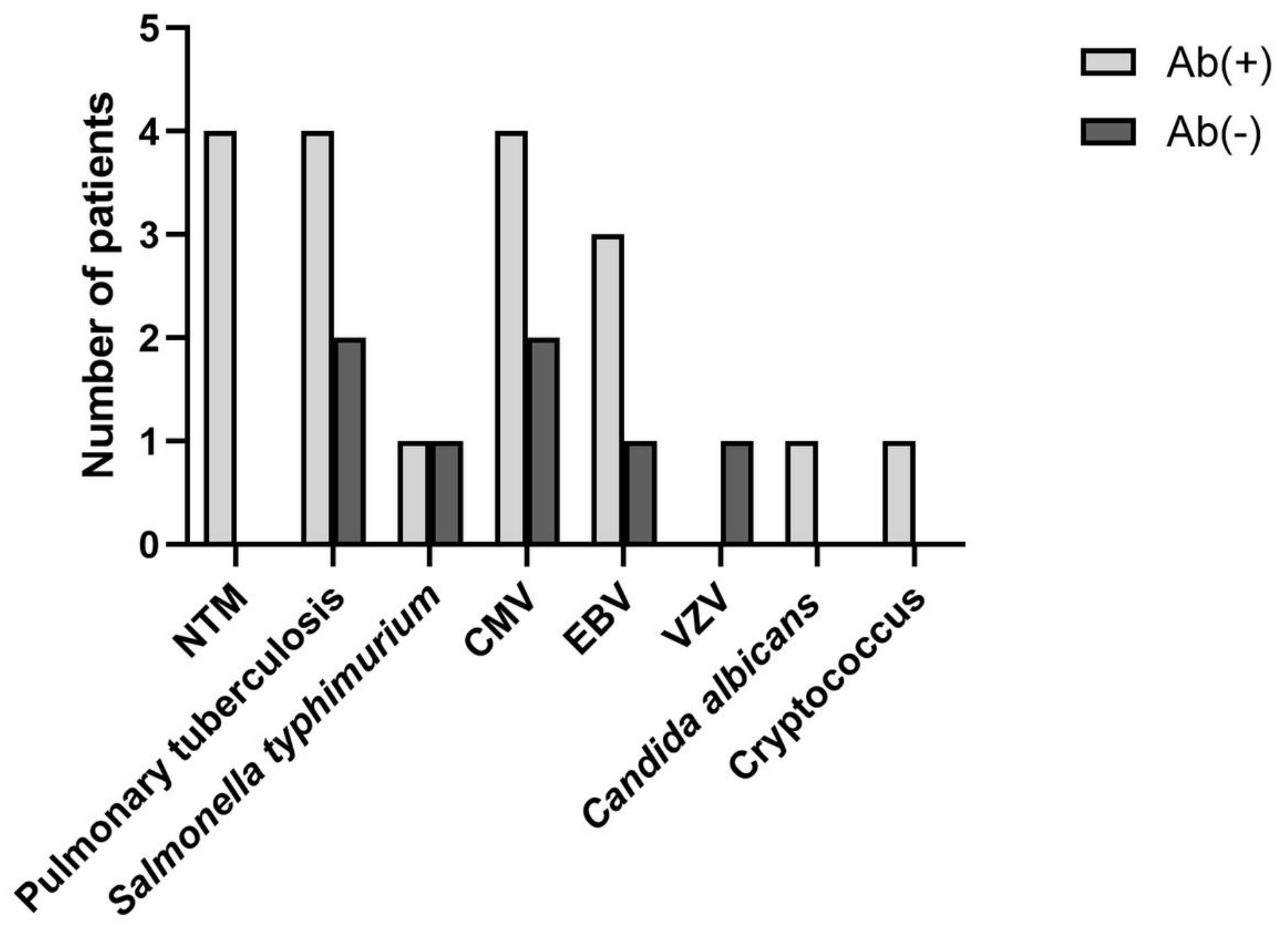

Figure 4

Coinfected pathogens and infections among patients in group 1P NTM= Nontuberculous Mycobacterium; $\mathrm{CMV}=$ Cytomegalovirus; $\mathrm{VZV}=$ Varicella zoster virus; $\mathrm{EBV}=$ Epstein-Barr virus 
A

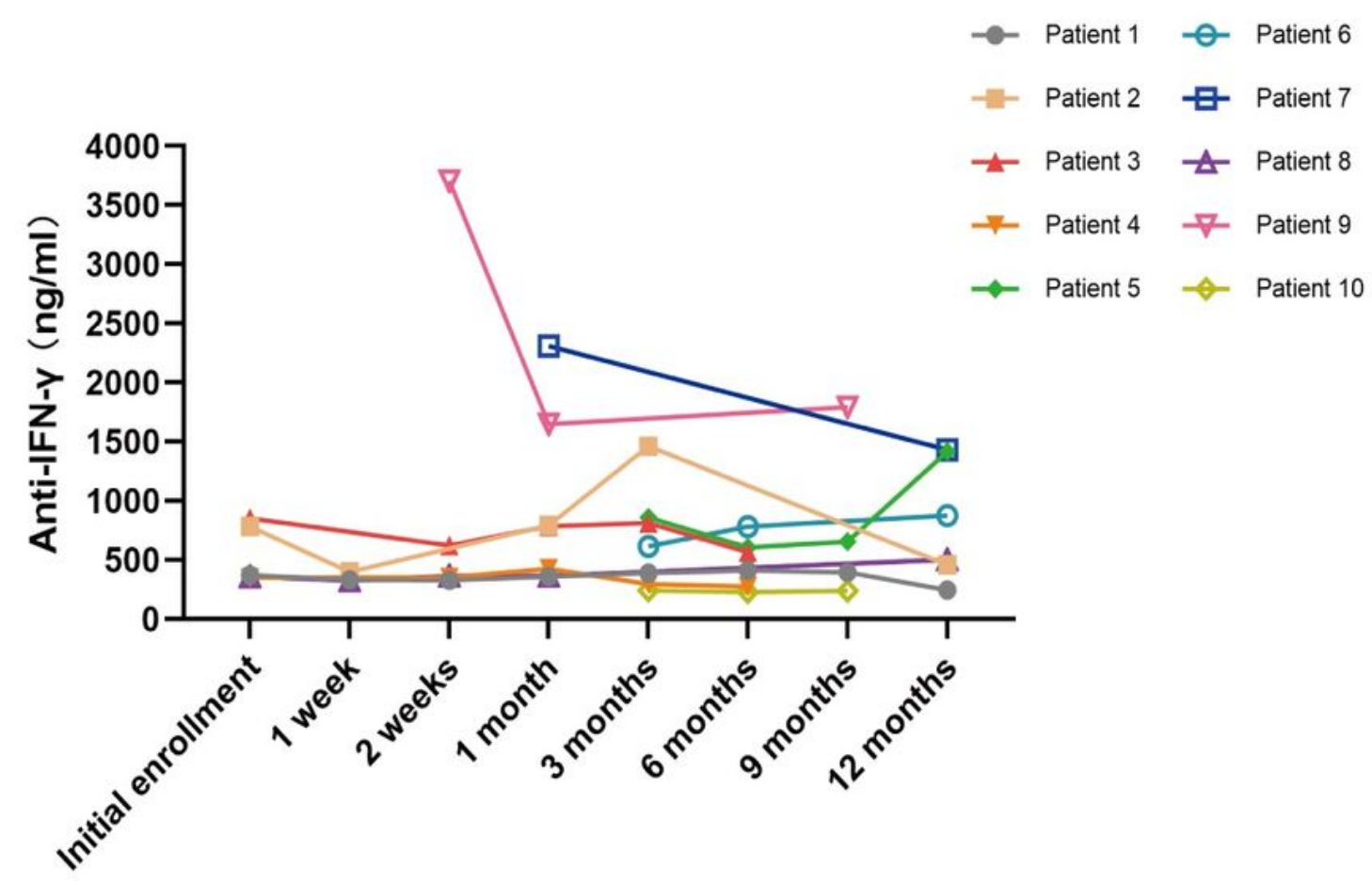

Time

B

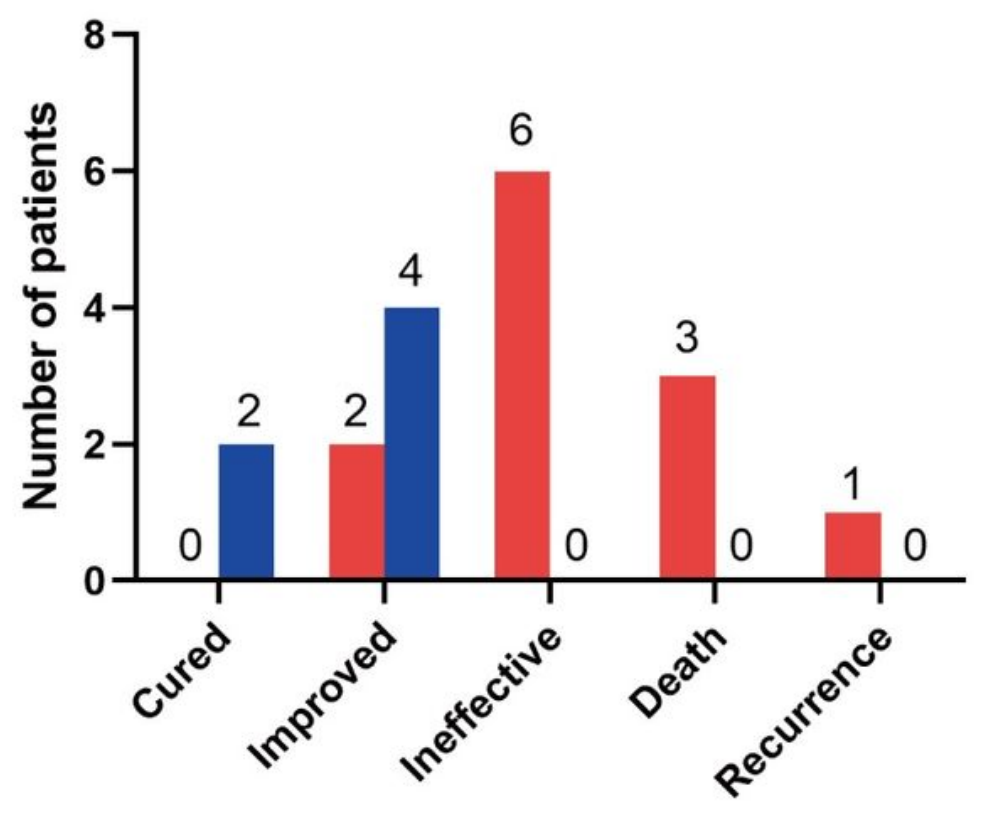

$\mathrm{Ab}(+)$

- $\mathrm{Ab}(-)$

\section{Figure 5}

Clinical courses and outcome of patients in group $1 \mathrm{a}$. Dynamic changes in autoantibodies throughout the course of disease b. Clinical outcome of patients in group 1 after 12 months of treatment Cured = The symptoms and signs disappeared completely, with the lesions in the lung and other involved organs markedly or completely absorbed and the laboratory indexes related to infection normalized. Improved = The symptoms and signs improved, with no new signs or symptoms of lung or other organ infection 
appearing; the lesions in the lungs and other organs were absorbed or there was no obvious deterioration, and the laboratory indicators related to infection were improved. Ineffective $=$ The symptoms and signs resumed or worsened, or new symptoms or signs of lung or other organ infection occurred, with progression or no improvement in the lesions in the lungs or other organs and worsening or lack of improvement in the laboratory parameters related to infection. Recurrence = After effective treatment, the symptoms and signs improved or the pathogen was no longer detected, followed by the reappearance of the symptoms and signs and detection of pathogen infection.

\section{Supplementary Files}

This is a list of supplementary files associated with this preprint. Click to download.

- Table.docx 